\title{
Preference for different auditory stimulus sequences in various age groups'
}

ERNEST E. BOESCH, PAUL B. BALTES ${ }^{2}$ AND LOTHAR R. SCHMIDT UNIVERSITAET DES SAARLANDES, GERMANY

Male Ss ranging in age from 8 to 20 years were presented with all possible pairs of 8 different auditory stimulus sequences consisting of different numbers of single stimuli within a $10 \mathrm{sec}$ interval. The number of single auditory stimuli varied in logarithmic steps from 30 to 100 per $10 \mathrm{sec}$. Ss were asked to make preference judgments with regard to pleasantness. Analyses of variance yielded significant age differences in preference measures. Older Ss preferred increasingly slower stimulus sequences.

In recent years such closely interrelated constructs as optimal stimulation (Leuba, 1962), optimal level of activation (Fiske \& Maddi, 1961; Duffy, 1962) and optimal mental or personal tempo (Mishima, 1965) have attracted increasing attention. One of the necessary steps in developing such constructs consists of studying the psychological reactions to external stimulus patterns. Fiske \& Maddi (1961) suggested that an index of the degree of pleasantness might be one of the feasible measures for the affective reaction of a $\mathrm{S}$ to a specific stimulus pattern. Furthermore, Fiske and Maddi (1961) considered chronological age as one of the most important determinants for individual differences in preferential levels of activation and/or personal tempo, besides other factors such as sex or cultural membership.

\section{Subjects}

In a cross-sectional study six comparable male samples with mean ages of approximately $8(\mathrm{~N}=29), 10$ $(\mathrm{N}=29), 12(\mathrm{~N}=28), 14(\mathrm{~N}=32), 17(\mathrm{~N}=37)$, and $20(\mathrm{~N}=27)$ years were observed.

\section{Stimuli and Procedure}

Groups of five Ss each were presented in a complete paired-comparison design with all possible pairs of eight auditory stimulus sequences, the order of the resulting 28 pairs being defined by chance. The auditory stimulus intervals consisted of a $10 \mathrm{sec}$ sequence of single auditory stimuli. The frequency of each single tone within the $10 \mathrm{sec}$ sequence was $1000 \mathrm{cps}$, the intensity about 55-60 dB, and the duration $50 \mathrm{msec}$. The eight stimulus sequences differed in the number of single tone units spaced equally within the $10 \mathrm{sec}$ interval. Following a study by Pollack (1952), the number of single stimuli was chosen to vary in logarithmic stepg from three to 100 per $10 \mathrm{sec}$, i.e., 3, 5, 8, 13, $22,37,61$, and 100 .

After some training trials, the 28 pairs were given from a tape recorder placed at a distance of about $5 \mathrm{~m}$ from the Ss. Both of the two different stimulus sequences composing each pair were presented succes- sively with a pause of 3 sec separating them. The pause between each pair was $10 \mathrm{sec}$. During the latter pause the Ss indicated on a mimeographed sheet which one of the two stimulus patterns they liked best. After one week all Ss were run again under the same procedure.

\section{Resulis}

The number of preferences per stimulus sequence was computed and used as a raw score for each S. Since the preference measures were combined over both sessions, each $\mathrm{S}$ had a total of 56 preferences distributed over the eight stimulus sequences.

After the homogeneity of variances was found to be satisfactory, a separate analysis of variance was performed for each stimulus sequence with the single factor being age in six levels. The analyses of variance revealed for five of the eight stimulus sequences $(5,8$, 13, 61, 100) significant age differences, the age differences for the stimulus sequences 8,13 , and 100 being at the $1 \%$ level of confidence, those for the 5 and 61 at the $5 \%$ level of confidence.

For the purpose of graphical clarity, Fig. 1 summarizes the mean preferences for the 8-, 14- and 20yearmolds only. It is evident that the age differences obtained by the analyses of variance signify that, with

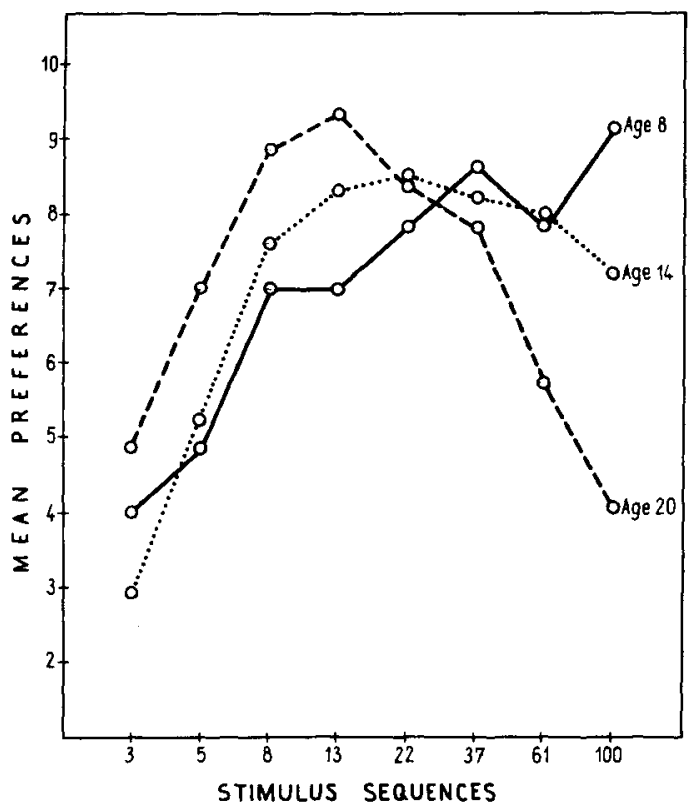

Fig. 1. Mean preferences of three age groups for eight stimulus sequences. 
Table 1. Mean Preferences for Stimulus Sequences (SS) Six Age Groups

\begin{tabular}{ccccccccc} 
Age/SS & 3 & 5 & 8 & 13 & 22 & 37 & 61 & 100 \\
\hline 8 & 4.0 & 4.9 & 7.0 & 7.0 & 7.8 & 8.5 & 7.9 & 9.1 \\
10 & 3.7 & 4.8 & 5.8 & 7.6 & 8.0 & 8.3 & 9.0 & 8.9 \\
12 & 2.6 & 4.7 & 6.7 & 8.8 & 8.8 & 9.0 & 7.7 & 7.8 \\
14 & 2.9 & 5.2 & 7.6 & 8.3 & 8.5 & 8.2 & 8.0 & 7.2 \\
17 & 3.4 & 5.8 & 7.2 & 8.7 & 8.7 & 8.7 & 7.7 & 5.8 \\
20 & 4.9 & 7.0 & 8.9 & 9.3 & 8.4 & 7.8 & 5.7 & 4.1 \\
\hline
\end{tabular}

higher ages, increasingly slower stimulus sequences are preferred. The age sequence for mean preference is 100 for the 8-year-olds, 61 for the 10-, 37 for the 12-, 22 for the 14- and 17-, and 13 for the 20-year-old Ss. Especially distinct is that the relation between stimulus sequence and mean preference is approximately parabolic for the age groups of 12 to 20 , while it is approximately linear for the 8- and 10-year-olds. It is, however, not feasible to extrapolate this linear relationship to higher stimulus sequences since it might be that the presentation of stimulus sequences with more than 100 single stimuli per 10 sec interval would yield a parabolic relationship for the younger age groups also. Discussion

The present results are in partial agreement with sporadic earlier studies. With regard to metronome beats, for instance, Wallin (1911) and FrischeisenKohler (1933) had found that adults preferred, on the average, a tempo of 20 respectively 19 beats per 10 sec interval, a finding which was recently substantiated by Mishima (1965). This seems to be in fair agreement with the sequences found in this study for the 14- to 20year-olds. On the other hand, the developmental trend toward preference for slower stimulus sequences has not been fully supported by earlier investigations. Only Frischeisen-Kohler (1933) reported a distinct preference for higher metronome tempo in 7- to 9-year-old children.

With regard to the interpretation of age differences, it was made clear by Schaie (1965) and Baltes (1968) that age differences cannot be considered as pure age effects, since age differences might be a confounded result of age and generation effects. Nevertheless, the authors lean toward an interpretation of the present data within a context of developmental personality theory. It seems plausible that there exists a kind of compensatory relationship between external and internal stimulation in the sense of Leuba (1962). For the age range under consideration, one might suggest that the amount of external stimulation to achieve an optimal level of activation is reduced in favor of the increasing internal stimulation going along with individual development. Such hypotheses about the obtained age differences, however, can only be tested by systematic application of longitudinal and/or cross-sectional sequences.

\section{References}

BALTES, P. B. Longitudinal and cross-sectional sequences in the study of age and generation effects. Human Develpm., 11, 1968, in press. DUFFY, E. Activation and behavior. New York: Wiley, 1962.

FISKE, D. W., \& MADDI, S. R. Functions of varied experience. Homewood: Dorsey Press, 1961.

FRISCHEISEN-KOHLER, IDA. Das personliche Tempo. Eine erbbiologische Untersuchung. Leipzig: Thieme, 1933.

LEUBA, C. Relation of stimulation intensities to learning and development. Psychol. Rep., 1962, 11, 55-65.

MISHIMA, J. Introduction to the morphology of human behavior. The experimental study of the mental tempo. Tokyo: Toyo Publishing Co., 1965.

POLLACK, J. Auditory flutter. Amer. J. Psychol, 1952, 65, 544-554. SCHAIE, K. W. A model for the study of developmental problems. Psychol. Bull, 1965, 64, 92-107.

WALLIN, J. E. V. Experimental studies in rhythm and time. Psychol. Rev., 1911, 18, 100-131. Notes

1. The authors wish to express appreciation to R. Haas, C. D. Kaulin, H. Kramer, Ursula Mainberger, Christine Schumann, and H. Zayer for their valuable assistance in data collection and data analysis, and to S. F. Johnsen for a critical reading of the manuscript.

2. Now at Department of Psychology, West Virginia University, Morgantown, W. Va. 